\title{
Foldscope as a Preliminary Diagnostic Tool for Field Veterinarians
}

\author{
R. Jayashree*, M. Tajunnisa, B. Kavitha Rani, K. T. Lakshmishree, \\ P. Sheela, M. Dhoolappa and B. S. Pradeep \\ Veterinary College, Shimoga, India \\ *Corresponding author
}

\section{A B S T R A C T}

The Foldscope is one of the latest inventions in the field of microscopy. It is a small, handheld, paper-based microscope with a light-emitting diode (LED) light source. It can be held up to the eye for visualization of slides; however we have to secure it to the camera lens of a smart phone by using the magnetic ring supplied along with the kit. An attempt was made

\section{Keywords}

Foldscope, Workshop, Veterinary diagnosis-imagesmobile phones

\section{Article Info}

Accepted:

07 August 2020 Available Online: 10 September 2020 to probe the utility of the Foldscope in Veterinary diagnosis as part of a project. Different kinds clinical samples submitted to Veterinary College Hospital during the period 2018-19 were visualized using Foldscope. Apart from this various histological and histo-pathological specimens, parasitological slides, microbial samples, rumen liquor, semen samples, skin scrapings and clinical samples requiring microscopy were visualized using Foldscope. A series of workshops and hands on training was offered to Veterinarians to evaluate its usage in day to day clinical practice. Amongst the 153 participants majority $(84.97 \%)$ were Veterinarians and the remaining 15.03 per cent of them were from other fields. The Veterinarians were excited to observe sperm motility from bull semen samples and 40.52 per cent (62), of them expressed its utility to assess the quality of the semen before using the batches supplied to them for artificial insemination. Rumen liquor collected from ruminants was also visualized using Foldscope. Majority of the participants [50.33per cent (77)] felt that Foldscope could be used for diagnosing ruminal disorders based on the activity of ruminal protozoans and ciliates. Majority of the participants [91.50 per cent (140)] were satisfied with the information given about the Foldscope in the workshops, 96.73 per cent (148) were satisfied with the demonstration done using Foldscope. 94.12 per cent (144) of the participants were able to load slides to the Foldscope and 90.20 per cent (138) of them were able to capture images using smart phone cameras. Majority of them 79.08 per cent (121) expressed that the magnification of the lenses should be increased to visualize certain microbes and blood protozoans. Overall $135(88.24 \%)$ participants recommended Foldscope as an immediate tool for diagnosis.

\section{Introduction}

Microscopy is an integral clinical diagnostic tool for Veterinary Clinicians. Veterinarians practicing under rural Veterinary Dispensaries have less access to microscopes or any other diagnostic tool. In the recent days mobile phone based microscopes are being used to a limited extent. One of the latest inventions in the field of microscopy is the Foldscope. A 
Foldscope is an optical microscope that was developed by Manu Prakash of Stanford University, USA as a part of frugal science movement (Cybulski et al., 2014). The Foldscope weighs just 8 grams has the capacity to provide magnification from $140 \mathrm{X}$ to 2,000X. Foldscope can be attached to a smartphone with the help of magnet for the user to take pictures of the magnification. It is compact and light, especially when compared with conventional field microscopes. Its minimalistic, scalable design is inherently application-specific instead of generalpurpose, providing less functionality at dramatically reduced cost (Joshi et al., 2018). For example, in situ examination of specimens in the field provides important opportunities for ecological studies, biological research, and medical screening. Foldscope shall be used in a different domain of microscopic study that would help people to better understand the microscopic world around us including microorganisms and microstructures (Denarol et al., 2018). Foldscopes are compact and light is so affordable and can be used anywhere as it does not require external electricity power supply. It was described that the Foldscope is a relatively inexpensive tool for understanding down-to-earth applications in plant science (Devi et al., 2019).

In the field of agriculture experiment using Foldscope to study the variability present in cereals, pulses, oilseeds and commercial crops for various parameters like seed morphology, seedling characters (root, shoot, pigmentation), leaf characters (leaf serration, leaf sheath), flower characters (calyx, corolla, androecium, gynaecium) and other special features were studied (Jayateertha et al., 2018). The variability is an important part of genetic resources, which enables breeders to exploit it for interested trait and in desired direction for crop improvement all over the world.
An attempt was made to probe the utility of Foldscope in the Veterinary diagnosis. Foldscope was used to visualize clinical samples and fixed specimens preserved in the laboratories of Anatomy, Pathology, Parasitological and Microbiology at Veterinary College, Shimoga, KVAFSU, Karnataka, India. The routine glass slides were used to prepare the samples to be evaluated in the Foldscope. Slides made of card board paper supplied along with Foldscope kit were also used to prepare liquid samples. The images were captured using mobile phone cameras that give an opportunity to share the images to experts in the Veterinary diagnosis for more precise investigation.

Later after getting convinced a series of workshops were conducted to practicing Veterinarians, researchers involved in the use of microscopes and to laboratory technicians to validate the use of Foldscope. The opinion of the participants on utilization of Foldscope was analysed to arrive at a conclusion whether to recommend Foldscope as a as a tool to be used for routine diagnosis.

\section{Materials and Methods}

Foldscope an origami-based microscope that was procured as part of DBT funded project at Veterinary College, Shimoga, KVAFSU, Karnataka, India. The basic kit supplied contains an unassembled Foldscope along with optical components of $140 \mathrm{x}$ magnification spherical ball lens. Its mechanical parts are printed on cardstock paper (Fig. 1A). Together with the basic kit, the sample-mounting components a LED torch with a battery for illumination is supplied. The basic kit also includes magnets that can be stuck onto the Foldscope to attach it to a smart phone, allowing the user to take pictures of the magnification (Fig. 1A). 


\section{Assembling the Foldscope}

The Foldscope is supplied as different parts printed on to a sheet allowing easy assembly following the instructions given (Fig. 1A \& 1B). Foldscope alters only the shape and size of the microscope. The sample to be studied is still mounted on a glass slide, and is appropriately inserted in the stage of the Foldscope. It is extremely space-efficient, tool. The total optical path length from the light source to the last lens surface is about $2.7 \mathrm{~mm}$, while that of a conventional microscope is around $300 \mathrm{~mm}$. The great magnification is achieved by exploiting the fact that magnification is inversely proportional to the ball-lens diameter.

\section{Visualization of specimen samples}

Several preserved samples available in the laboratories of Anatomy, Pathology, Parasitology and Microbiology Departments of Veterinary College, Shimoga, KVAFSU, Karnataka, India were visualized using Foldscope and the images were captured. (Fig. 2 A, B \& C). Histological section cut specimens maintained in the Veterinary Anatomy laboratory which are already stained and mounted by routine procedures were selected for visualization. For example the microscopic slides of the tissues of internal visceral organs like lung, liver, intestine, cardiac muscle, kidneys, rumen, reticulum, omasum, abomasum and several such samples of different tissues were visualized successfully (Fig. 2 A).

Likewise the routinely microscopic slides preserved in Veterinary pathological laboratory were also visualized and the pictures were documented. The diseased tissues of the visceral organs like heart, liver, kidney, lungs revealing cell proliferation, oedematous tissues, haemorrhages, congestion, lobulations, cirrhosis, fibrotic conditions etc., and cancerous conditions like malignant melanoma were also visualized (Fig. 2B).

The vectors which are intermediate host for various protozoan and infectious diseases are collected and preserved in the Department of Parasitology were also studied using Foldscope. These vector species affecting domestic animals are differentiated by their various body parts using microscope. The parts of ticks, Lice, Flies and different stages of intestinal parasites were also visualized using Foldscope. Filtered and centrifuged faecal sample were visualized by mounting the samples to the slides and were visualized. Neat blood sample covered with cover slip was also seen using Foldscope to identify haemo protozoans (Fig. $2 \mathrm{C}$ ).

\section{Visualization of Veterinary clinical samples}

Different kinds clinical samples submitted to Veterinary College Hospital during the period 2018-19 were visualized using Foldscope. (Fig. 2 D) Attempts were also made to visualize liquid samples like semen, rumen liquor, urine samples and to capture video images using mobile cameras. The methodology to mount various clinical samples was also standardized.

The samples were prepared on routine glass slides as well paper slides provided along with the kit was also used. In this study we have used the paper slides with suitable holes supplied along with the kit to visualize the liquid samples. One side of the holes were covered with cellotape. After dropping the liquid sample in the wells of the slides the hole was also closed with cellotape. This prevented the seepage of liquid samples while visualizing the images using Foldscope and capturing images (Fig. 1B). Hair samples brought for forensic identification were also visualized. 
The vaginal impression smears of bitches in oestrus were collected. They were stained with 1: 9 Giemsa stain for 15 minutes and visualized using Foldscope. The cornified epithelial cells to the extent of more than 70 per cent reveals the suitable time of mating of the bitches (Fig. 2 D).

The urine sample of suspected cases of urinary calculi were collected and centrifuged of and a drop of the sediment was placed on a slide and secured with coverslip and visualized in Foldscope to identify the presence of urate crystals (Fig. 2 D).

The feed samples are often tested for fungal contamination. The sample will be cultured in the laboratory condition. The fungal growth was smeared on to slides and stained with Lacto-phenol cotton blue stain. This was covered with coverslip and secured with cellotape and then mounted to Foldscope for visualizing the presence of some of most common fungal contaminants like the Aspergillus species (Fig. 2 D).

\section{Foldscope workshop for Veterinarians and other researchers}

A series of workshops and hands on training was organized for the Veterinarians and other researchers involved in microscopy was arranged during the period 2018-19 at Veterinary College, Shimoga. A total of 153 participants comprising of Veterinarians serving in the Department of Animal husbandry services, GOK, Karnataka milk federation, Veterinary Colleges and private practioners were involved in the workshop. Along with them researchers using microscopy and laboratory technicians were also trained to use the Foldscope. The online tutorial videos pertaining to the assembly and use of Foldscope was projected to the participants so as to enable them to understand more clearly about this new instrument.
They were made to assemble the basic kit, prepare slides from different samples both on glass slide and as well on paper slides. The liquid samples like semen, urine, rumen liquor collected from various domestic animals like dog, cat, cattle, buffalo, sheep and goat were also visualized using Foldscope. Apart from this section cut tissue samples of lung, liver, vaginal impression smears, ticks, mites, lice and hair samples of different species were also visualized by the participants. They were trained to focus the image and capture the image using smart phone cameras (Fig. 1 B). The overall opinion on the use of Foldscope as a diagnostic tool was evaluated from the by way of structured questionnaire prepared for the purpose.

\section{Statistical method used}

Frequency and percentage were used for the statistical assessment of the opinion expressed by the participants using Microsoft Excel tools.

\section{Results and Discussion}

The Foldscope parts were successfully assembled by all the participants (Fig. 1B). Histological, histo-pathological and parasitological specimen slides were visualized and images captured using smart phone cameras (Fig. 2A, B \& C).

\section{Foldscope for visualization of various samples}

Various clinical samples like blood and faecal samples were mounted to routine glass slides covered with cover slip and visualized. A drop of semen sample was placed on to the glass slide and covered with coverslip. It was mounted on Foldscope and visualized for sperm motility. The video images were recorded in smart phone cameras. Similarly the movement of ciliates and protozoansin 
rumen liquor samples were also successfully visualized. Urate crystals from urine samples collected from suspected cases of urolithiasis were recorded. The vaginal impression smears were collected in glass slides and were stained with Giemsa and visualized using Foldscope. Faecal sample for diagnosis of parasitic eggs, coccidial oocysts, neat blood for seeing the haemo-protozoans, fungal spores from feed samples and hair samples of different species were also visualized using Foldscope and the images were captured (Fig. 2D). The collections of images were also posted on to the https://microcosmos.foldscope.com/wp.

\section{Opinion on the application of Foldscope}

Introduction of Foldscope was made to the Veterinarians by way of series of workshops conducted during the period from 2018-19. Opinion on the application of Foldscope in Veterinary clinical diagnosis was collected from 153 participants of the different workshops. Amongst the total participants majority $(84.97 \%)$ were Veterinarians and the remaining 15.03 per cent participants from other fields (Table 1). 89.54 per cent (137) of them were attending the Foldscope workshop for the first time on Foldscope and the rest 9.80 percent (15) were attending the workshop for the second time. 61.44 per cent of the participants were aware of the instrument called Foldscope and they came to know about the Foldscope from friends, social media, project PI or through all means and were eager to learn its utility (Diagram 1A).

The participants were assessed for the present scenario of the facilities available and their dependency on diagnostic resources. Amongst the participants 49.02 per cent (75) of them said they have a microscope in their hospitals whereas the remaining Veterinarians expressed they don't even have a microscope in their hospital. Even though the microscope were available with less 50 per cent of the Veterinary dispensaries majority of them expressed they are not supplied with slides or stains to make use of the available microscope.

Amongst the participants $132(86.27 \%)$ of them depended on various facilities for sending their clinical samples (IAH \& VB24(15.69 \%), Govt Labs -64 (41.83\%), Private Labs-9 (5.88\%), and 22.88 percent (35) where depending on more than one of the facilities (Diagram 1B).

Among them only 44 (28.76\%) of them have attended some workshops/trainings organized at various places [Veterinary college, Shimoga (30), Karnataka Veterinary Council (6) and outside Karnataka (8)] to upgrade their skill in laboratory diagnosis, whereas majority $109(71.24 \%)$ of them have never attended any such workshops in the aspect of laboratory diagnosis (Diagram 1C).

Majority of the participants were satisfied with the information given about the Foldscope 91.50 per cent (140) during the workshop. They were glad to learn and use the available online tutorial on foldscope. Majority 94.77 per cent (145) of them expressed satisfaction on the topics discussed during the workshop and 96.73 per cent (148) were satisfied with the demonstration done using Foldscope. 94.12 per cent (144) of the participants were able to load slides to the Foldscope and 90.20 per cent (138) of them were able to capture images using smart phone cameras. Overall, 88.24 per cent (135) of the participants recommended Foldscope as an immediate tool for diagnosis (Table 1).

Majority of the participants 67.97per cent (104) opined that they were able to visualize liquid samples with ease and 2.61 per cent (4) of them expressed they were scared that the liquid samples might spill and harm them. 
The Veterinarians recommended the Foldscope for observation of Sperm motility 40.52 per cent (62), Rumen fluid examination 50.33 per cent (77) for diagnosing ruminal disorders based on the activity of ruminal protozoans and ciliates.

The Veterinarians $45.75 \%$ (70) expressed that they would carry the Foldscope in their practice kit field diagnosis provided the following improvement that could be made in designing the Foldscope. Majority of them $79.08 \% \quad$ (121) expressed that the magnification of the lenses should be increased to visualize certain microbes and blood protozoans. Because of this major drawback they were not be able to visualize blood smears which are very essential under routine diagnostic procedure. The following opinions were given by different participants for effective utilization of Foldscope in field diagnosis.

Must be improved because the focusing sheets are of poor quality.

Can be made still easier to observe

Some improvements need to be done for visualizing liquid samples

Moving from one field to another may be made easier

It was difficult to focus /visualize histological section/slides

Coarse adjustment needs to be improved Request to change the Foldscope material with other acrylic or fiber material.

\section{Table.1 Review of the Foldscope workshop}

\begin{tabular}{|c|c|c|c|}
\hline \multicolumn{2}{|l|}{ Participant Details } & $\%$ Yes (*) & $\%$ No (*) \\
\hline \multicolumn{2}{|l|}{ Are you a Veterinarian? } & $84.97(130)$ & $15.03(23)$ \\
\hline \multicolumn{2}{|l|}{ Is this your first workshop? } & $89.54(137)$ & $9.80(15)$ \\
\hline \multicolumn{2}{|l|}{ Have you ever heard of the device like foldscope? } & $61.44(94)$ & $38.56(59)$ \\
\hline \multicolumn{4}{|c|}{. Opinion about the Foldscope Workshop } \\
\hline \multirow{2}{*}{\multicolumn{2}{|c|}{ Did you get enough information of Foldscope? }} & Satisfied & Not Satisfied \\
\hline & & $91.50(140)$ & $8.50(13)$ \\
\hline \multicolumn{2}{|c|}{ Were the topics discussed during the workshop was the useful? } & $94.77(145)$ & $5.23(8)$ \\
\hline \multicolumn{2}{|c|}{ Was the demonstration done in the Foldscope workshop was useful? } & $96.73(148)$ & $3.27(5)$ \\
\hline \multicolumn{2}{|l|}{ Were you able to load slides and visualize the slides? } & $94.12(144)$ & $5.88(9)$ \\
\hline \multicolumn{2}{|l|}{ Were you able to capture images in your mobile? } & $90.20(138)$ & $9.80(15)$ \\
\hline \multicolumn{2}{|l|}{ What were the samples you visualized in the workshop? } & \multicolumn{2}{|c|}{$\begin{array}{l}\text { Sperm motility, Tissue sample, Flea, } \\
\text { Uratecrystals, Rumen protozoan } \\
\text { motility }\end{array}$} \\
\hline \multicolumn{4}{|c|}{ Opinion about the visualization in Fold scope } \\
\hline \multirow[t]{2}{*}{$\begin{array}{l}\text { What was your opinion about visualization of liquid } \\
\text { samples? }\end{array}$} & Difficulty & Easy & $\begin{array}{l}\text { Scared if } \\
\text { samples may } \\
\text { spill }\end{array}$ \\
\hline & $26.14(40)$ & $67.97(104)$ & $2.61(4)$ \\
\hline \multirow{2}{*}{$\begin{array}{l}\text { Did you visualize the semen sample and observed the } \\
\text { sperm motility? }\end{array}$} & \multicolumn{2}{|c|}{ Yes } & No \\
\hline & \multicolumn{2}{|c|}{$66.01(101)$} & $33.99(52)$ \\
\hline \multirow[t]{2}{*}{ Overall impression about the workshop } & Good & Satisfactory & Poor \\
\hline & $45.75(70)$ & $50.33(77)$ & $2.61(4)$ \\
\hline \multirow{2}{*}{\multicolumn{2}{|c|}{ Do you recommend this as an immediate tool for diagnosis }} & Yes & No \\
\hline & & $88.24(135)$ & $11.76(18)$ \\
\hline
\end{tabular}

*Figures in the parentheses represent the actual numbers in figures 
Fig.1A Parts of the foldscope and assembling workshop
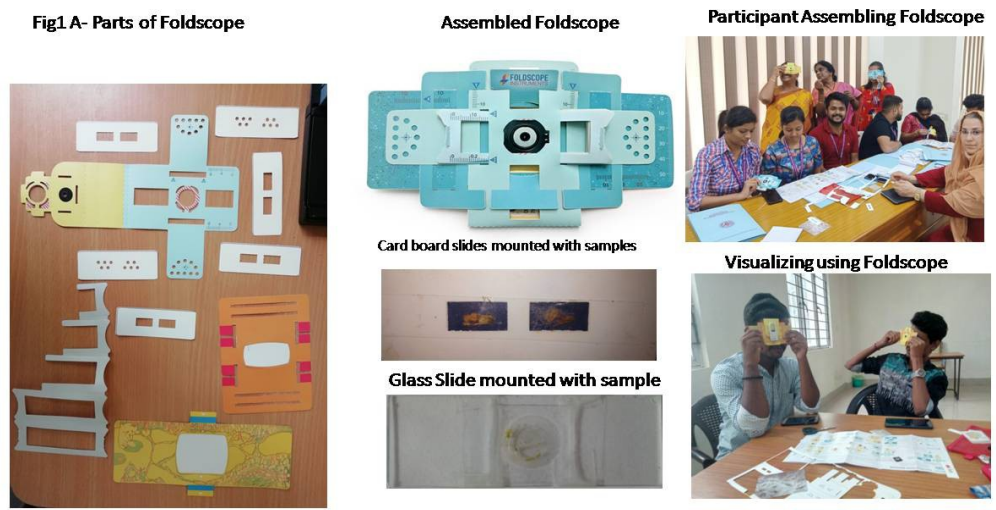

Fig.1B Loading slides in foldscope and visualizing
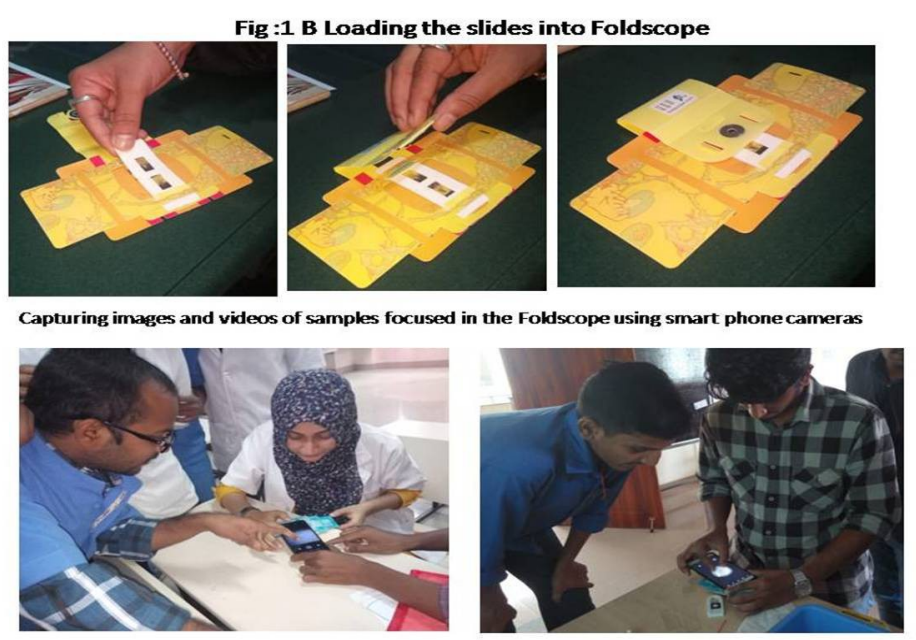

Fig.2A Visualization of histological slides

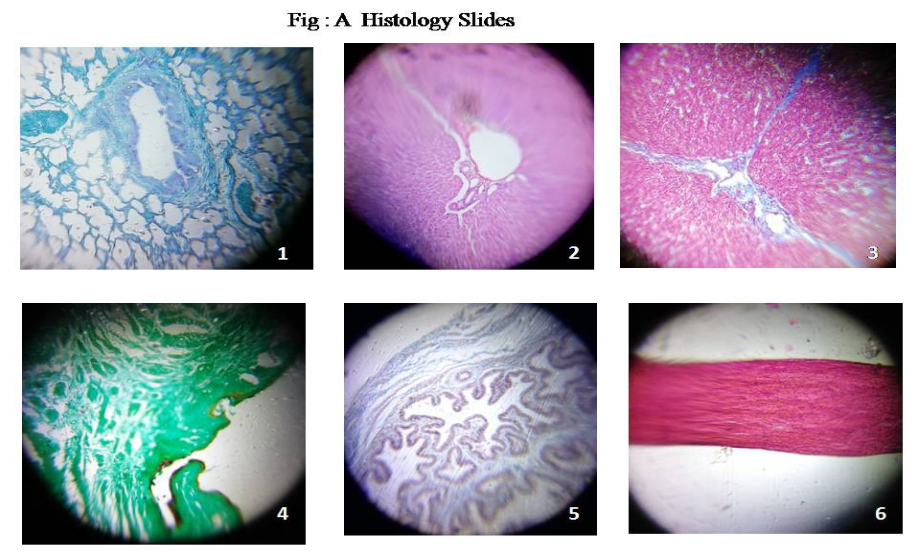

1. Lung- sheep, 2. Liver- cattle, 3. Liver- Pig, 4.Omasum- cattle, 5. Uterus 6.Nerve tissue 
Fig.2B Visualization of histo-pathological slides

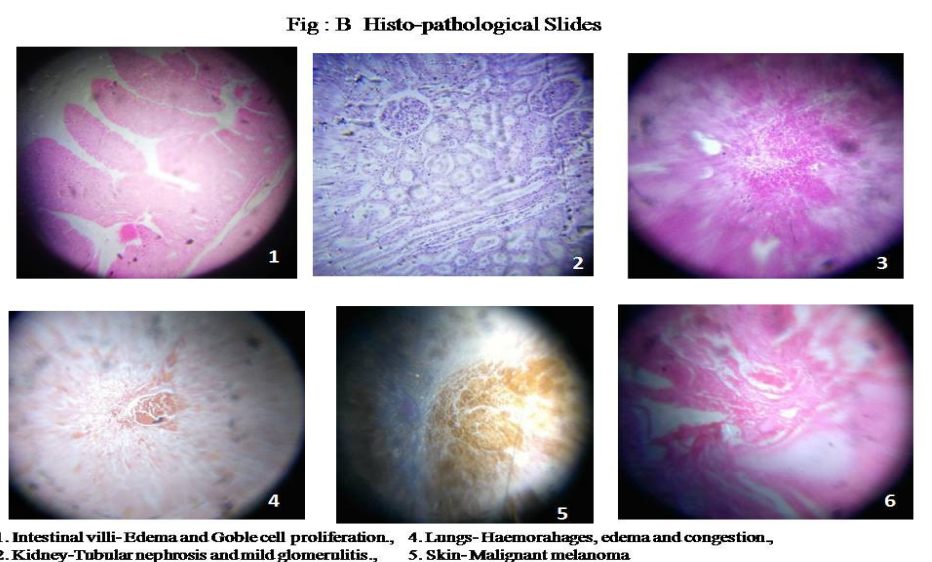
2.Kidney-Tubular nephrosis and mild glomernlitis., 5. Skin-Malignant melanoma

Fig.2C Visualization of parasitological specimen slides

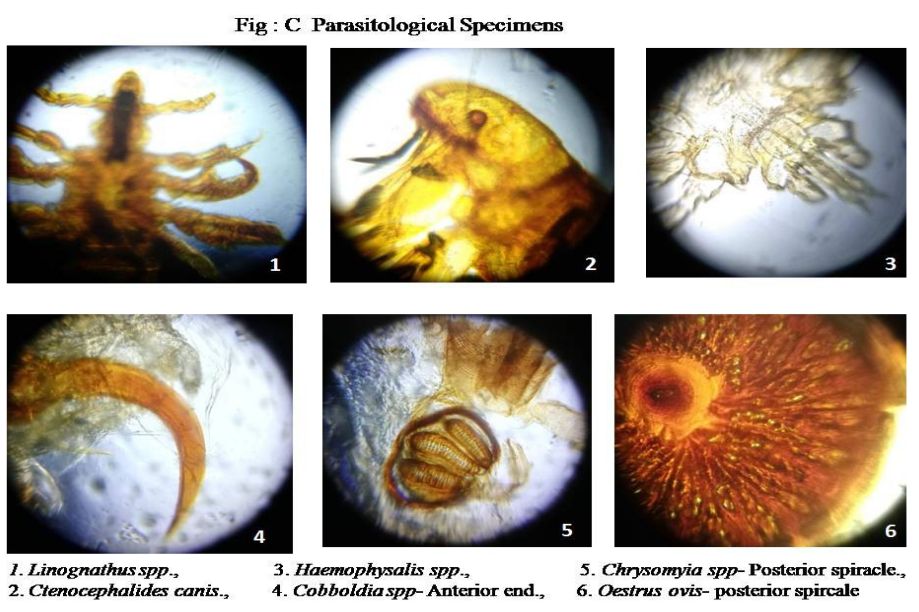

Fig.2D Visualization of clinical samples

Fig : D Veterinary Clinical samples
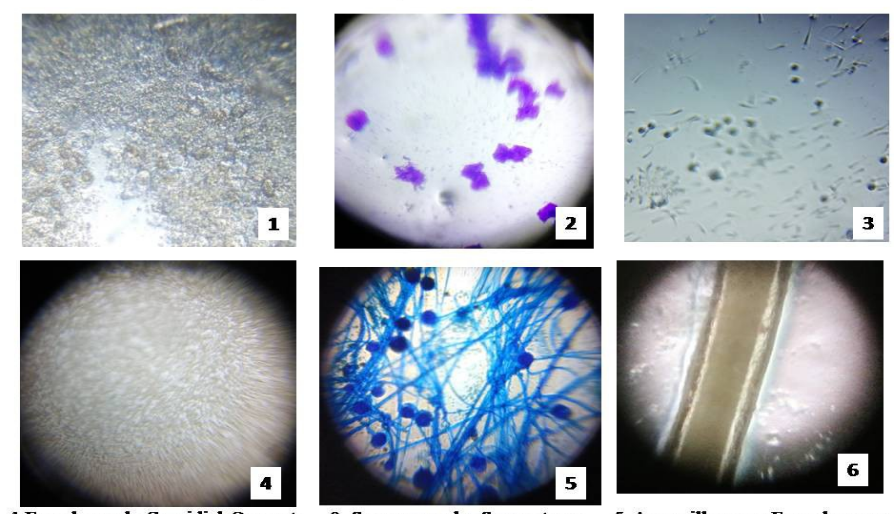

1.Faecal sample-Coccidial Ooccysts., 3. Semen sample
2. Dog Vaginal impression smears.,

5. Aspergillus sp.,- Fungal smears. 6. Hair Sample- Tiger 


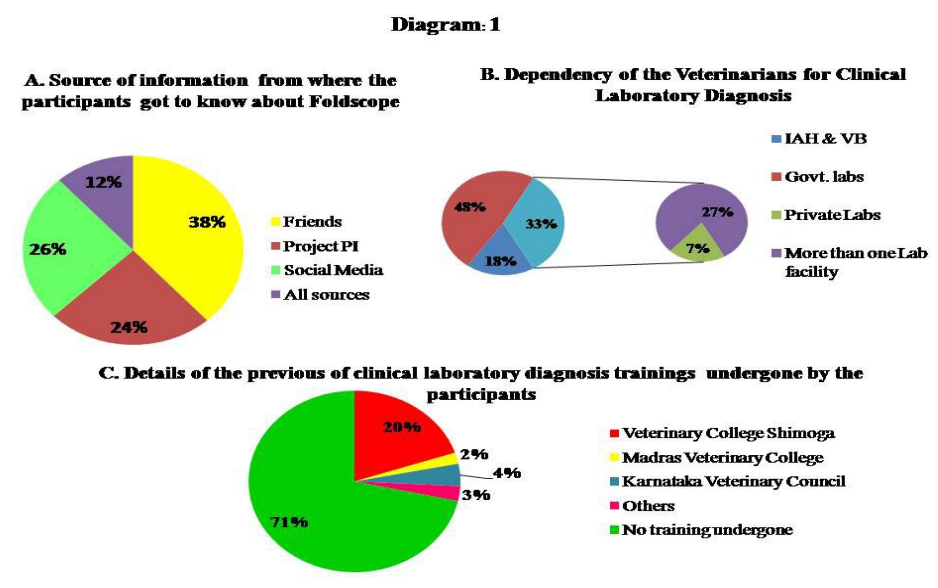

Foldscope was found to be an efficient tool to visualize various parasites and tissue samples with ease. As the Foldscope holds the same slide used in compound microscope, hence found to have multifarious uses such as to visualize day to day clinical samples presented in Veterinary hospital. Since it is unbreakable it can be carried by the Veterinarians in his field kit. Moreover, the images shall be captured using smart phone cameras helps in further magnification and provides an opportunity to save the images for further expert opinions. The Foldscope has been used to visualize protozoan and parasites (Ephraim et al., 2015, Bogoch et al., 2017). Theyfelt that the 140X magnification of Foldscope was easiest to use, when coupled with the digital zoom of the mobile phone camera that would provide adequate magnification to visualize $S$. haematobium ova. They also expressed the sensitivity of this device may be low because of a combination of some challenges with manually manipulating microscope slides underneath the lens, and the low infection intensities in the study setting. Foldscope as a tool to support taxonomic identification of Rhipicephalus sanguineous sticks on the field (Sanchez et al., 2018).A total of 257 ticks were collected from five neighbourhoods in the city of Chihuahua, Mexico. Representative morphological structures were analyzed for taxonomic identification with a stereoscope and a Foldscope. It was possible to identify key morphological structures such as palps, base of capitulum, eyes, anal groove, festoons, first coxa and spiracular plate on specimens of $7 \mathrm{~mm}$ in length or less. Foldscope is a tool that allows morphological identification of ticks on the field. It may be useful for epidemiological studies on the field and on social outreach programs aimed at raising awareness about vector-borne diseases.

The users of the Foldscope felt that they have problem in adjusting the platform for coarse and fine adjustment unlike in the compound microscope. They expressed that with regular use they may be able to handle it and find its suitability for certain of the samples. A comparative study on Foldscope and Monocular microscope was done and they expressed that though the Foldscope is priced less and there is an ergonometric problem when intense slide examination is required(Ephraim et al., 2015). Without the ability to switch between low and high power, slide investigation is difficult. The exploration of the slide is a difficult task, because movement of the slide and/or focus adjustment, can result in the need to realign the image/slide. They attempted to create a platform to stabilize the scope with simple support from a piece of packing Styrofoam that allowed the slide to be systematically 
observed with a bit less realignment. They suggested high quality cover slips to improve the image. Enumerated gradations on the cover slips would also help the investigator to know which parts of the slide they are observing. This is important for diagnostics. An adaption of the scope for the observation of continuous cell cultures would be helpful. They also expressed that the cell phone camera can do a lot of post image capture processing to magnify and improve the image. If a cell phone "APP" was developed to do some image processing like pixel intensity, cell counts and data processing, the scope would have greater research potential. Similar impression was felt by the participants of the Foldscope workshop as they were able to magnify the images after capturing in their smart phone cameras.

A study on Foldscope based methods to detect in-tissue antioxidant activity and secondary metabolites in pollen and stomata of Lantana camara revealed that the Foldscope can be used as an efficient tool to detect in -tissue activities of antioxidants and secondary metabolites in invasive alien plant Lantana camara (Priya et al., 2018). Foldcsope images revealed viable stained areas in the respective seeds, indicating live activities. They concluded that Foldscope can be a cheap, portable and powerful efficient biological tool to evaluate plant biology-based studies. Similar studies shall also be attempted by Veterinarians to visualise fodder crops, fodder seeds and grains fed to animals to ascertain their quality in terms of spoilage by fungal or infestation by insect pests. However, in this study it was attempted to visualize fungal spores in the spoilt dry fodder efficiently. Collected fungal samples were propagated in the laboratory and the stained spores were visualized efficiently. Sand and other unwanted particles mixed in concentrate feed were also visualized using Foldscope.
Histo-pathological slides like Haemorrhagic Congestion of lungs, kidney, liver, Myocardial Haemorrhage of different livestock and pet animals and laboratory animals were visualized from fixed slides of tissue and the images were captured with clarity in this study unlike the views expressed by others (Waliullah, 2018). The images acquired with Foldscope are little bit low contrast as compared to the conventional light microscopy acquired images. But it is possible to improve the image quality by using its own LED as a light source during the investigations. The mobile phone-based imaging device 'Foldscope' use of ball lens for convenient use and its magnification capacity to $140 \mathrm{x}$ was enough to the histopathological investigation of human blood samples, tissue samples beyond the requirement of the expensive optical microscope and with low resource clinical settings. Even pathologist can easily detect the tissue abnormality by analyzing the mobile phone microscope obtained images in mobile phone apps.

In this study Foldscope was used to visualize the vaginal impression smears of bitches. This is an important diagnostic method to arrive at the time of mating of the bitches. This will be of help to practicing Veterinarians. In one of the studies that highlights the usefulness of the Foldscope in cervical cytology, demonstrating it has substantial agreement with conventional microscopy (Naqvi et al., 2020). Its use could improve cytological interpretations in underserved areas and, thus, improve the quality of cervical cancer screening. Improvements in existing limitations of the device, such as ability to focus, could potentially increase its accuracy. They opined that overall, the Foldscope images were comparable to those obtained with conventional microscope and digital camera setup. This study demonstrates that the Foldscope lens has substantial agreement 
with conventional microscope camera. The accuracy of the Foldscope was $80 \%$, with a sensitivity and specificity of 85 and $90 \%$ for the High-grade squamous intraepithelial lesion (HSIL)/ Malignant (Mal) positive category, 80 and $83.3 \%$, for Lowgrade squamous intraepithelial lesion (LSIL), and 70 and $96.7 \%$ for Normal. This study highlights the usefulness of the Foldscope in cervical cytology. However, the use of Foldscope in the area of cancer tissues of domestic animals could be studied at large for early diagnosis and suggest suitable therapy for cure (Waliullah, 2018).

In a study on the comparison of mobile phone-mounted Foldscope and reversed-lens CellScope had sensitivities of $55.9 \%$ and $67.6 \%$, and specificities of $93.3 \%$ and $100.0 \%$, respectively, compared with conventional light microscopy for diagnosing Schistosoma haematobium infection in human in Ghana. With future improvements to diagnostic sensitivity, newer generation handheld and mobile phone microscopes may be valuable tools for global health applications (Ephraim et al., 2015). A similar application may also be thought of in diagnosing Schistoma sp. infection in cattle.

Urine samples from a dog suspected of urolithiasis were visualized using Foldscope. The urate crystals could be visualized with ease. This helped in early therapy for that condition avoiding surgical intervention. Similar experimental studies were conducted to standardize the procedure to mount urine samples and observe for crystals using Foldscope (Rebecca et al., 2015). In this study, it was determined that the calcium oxalate crystals could in fact be visualized with this low budget instrument Foldscope. Methods were developed to keep it flat so that the liquid urine sample shall not fall by using clamps to hold it and a light source appropriately placed. They expressed that further development is needed to validate the same in with patient samples. In the present study we have mounted the urine sample by holding the samples in paper slide in between the cello tapes (Fig. 1D). Determination of the full range of identifiable crystals and cells of diagnostic significance would expand the usefulness of this application. Its use in low budget/low tech regions of the world would be greatly advantageous

Several issues emerged, highlighting differences compared to using a glass or paper cardboard slide - e.g., holding the microscope up to a light source resulted in the liquid sample dripping on the observers face (!).In this study since the liquid samples were secured between cellotapes in the paper slides there was less chance for spillage. However, the participants expressed their concern about spillage of liquid samples on to eyes. But during the workshop majority of the participants were able to mount liquid samples and capture video images in their mobile (Fig. 3).

In conclusion the foldscope shall be efficiently used for preliminary diagnosis in Veterinary clinical practice. It is a handy tool that can be carried along with the routine kit as it is unbreakable and moreover does not require continuous electric power supply.

The images shall be captured to smart phone cameras and can be saved for further visualization permitting expert consultancy by sharing the images for precise diagnosis. However, it requires hands on training and the Veterinarian has to use it more often to get acquainted with Foldscope. Higher magnification lenses are definitely required to visualize the blood samples and faecal samples which are most frequent samples collected. It shall also be used as an educative tool to farmers to show the eggs of parasites, insect vectors, fungal contamination of feed 
and fodder in order to create awareness of hygienic animal husbandry practices.

Foldscope could be used in clinical and epidemiologic investigations in the near future with technical adjustments to increase diagnostic sensitivity, such as increasing the field of view and enabling magnification of different powers, in addition to validating the devices on other pathogens in the field of Veterinary diagnosis.

\section{Acknowledgement}

The project was funded by DBT (Foldscope Project (T) GOI 2018-19 by BT/IN/IndoUS/Foldscope/39/2015 dated 20/03/2018

\section{References}

Ali Naqvi, Niti Manglik, Ellen Dudrey, Cynthia Perry, Zuber D. Mulla and Jorge L. 2020. Evaluating the performance of a low-cost mobile phone attachable microscope in cervical cytology, BMC Women's Health 20:60, https://doi.org/10.1186/s12905-02000902-0.

Bogoch II, Ephraim RKD, Tseng D, Koydemir HC, Ozcan, A, Andrews J R. 2017. Evaluation of a Mo-bile Phone-Based Microscope for Screening of Schistosoma haematobium Infection in Rural Ghana. The American Journal of Tropical Medicine and Hygiene. 96(6): 1468-1471.

Cybulski J. S, Clements J, Prakash M..2014. Foldscope: Ori-gami-based paper microscope. PLoS ONE.; 9(6): e98781.

Ephraim RKD, Duah E, Cybulski JS, Prakash M, D'Ambrosio MV, Fletcher DA, Keiser J, Andrews JR, Bogoch II. . 2015. Diagnosis of Schistosoma haematobium infection with a mobile phone-mounted Foldscope and a reversed-lens CellScope in Ghana. Am J Trop Med Hyg 92: 1253-1256.

Frank Denaro1, Maya Gabriel1, Arsene Noe1, and Simon Nyaga. (2018). Developing Tools for STEM Education: The Foldscope, a Very Inexpensive Monocular Microscope for Biological research.doi:10.1017/S1431927618007 353 Microsc. Microanal. 24 (Suppl 1), Microscopy Society of America 2018.

Jayateertha Diwan, Kashappa Chikkanaragund, Suma TC, Mahadevaswamy Y S, Amaresh P R Badariprasad and R Lokesh. 2018. University of Agricultural Sciences, India, Assessment of Agro Biodiversity through the foldscope International conference on Plant Science, Natural Products, Medicinal Plants and Traditional Medicines November 15-16, 2018 | Paris, France Plant science \& Natural Medicine Volume 2, DOI: 10.4066/2591-7897C1-002.

Joshi N., Joshi S., Papule P., Bhosale S. 2018. Interpretation of physical properties like crystallanity of maize starch powder effectively by foldscope. International Journal Of Pharmaceutics \& Drug Analysis Vol.6, Issue 9, 592 598; http://ijpda.com.

Parada-Sánchez, S. G., Meléndez-Salcido, C. G., Hernández-Castaños, M. R., PradoÁvila, S. E., Adame-Gallegos, J. R. 2018. Evaluación de Foldscope, un microscopio de papel basado en origami útil para la identificación de garrapatas Rhipicephalus sanguineus. Acta Universitaria, 28 (4), 19-24. doi: http://doi. org/10.15174/au.2018.2134.

Priya Nischal and Arun Dev Sharma, Foldscope based methods to detect intissue antioxidant activity and secondary metabolites in pollen and stomata of Lantana camara, Research 
\& Reviews in Biotechnology \& Biosciences. .2018. Volume: 5, Issue: $1 \& 2$, PP: $15-$ 19.http://www.npajournals.org/journal. php?cid $=20 \&$ sh $=\mathrm{j}$,

Rebecca Calder, Daniel Stevens, Zev Leifer. 2018. Preliminary Studies in the Use of the Foldscope Paper Microscope for Diagnostic Analysis of Crystals in Urine: Issues in the Analysis of Liquid Sample and Potential Applications in Low Budget/Low Tech Regions of the World. New York College of Podiatric Medicine footprints, vol. 5, July.

Richard K. D. Ephraim, Evans Duah, James S. Cybulski, Manu Prakash, Michael V. D'Ambrosio, Daniel A. Fletcher, Jennifer Keiser, Jason R. Andrews and Isaac I. Bogoch. 2015. Diagnosis of Schistosoma haematobium Infection with a Mobile Phone-Mounted
Foldscope, and a Reversed-Lens CellScope in Ghana., Am. J. Trop. Med. Hyg., 92(6) pp. 1253-1256, doi:10.4269/ajtmh.14-0741.

Sundari Devi, N Thoudam Santosh Singh, Senjam Jinus S, Sukham Joybi Singh, Tracila Meinam, Lourembam Sanajaoba Singh, Mutum Seityavhani Devi, O Premila Chanu, RK Imotomba Singh and Thiyam Jefferson Singh. 2019. Under the foldscope: Relatively inexpensive tool for understanding down-to-earth applications in plant sciences, Journal of Pharmacognosy and Phytochemistry; 8(6): 30-34.

Waliullah A S M. 2018. Application of mobile phone-based portable microscopy in clinical histopathology: A feasibility study. Int. J. Clin. Biomed. Res. 4(2): 16-20.

\section{How to cite this article:}

Jayashree, R., M. Tajunnisa, B. Kavitha Rani, K. T. Lakshmishree, P. Sheela, M. Dhoolappa and Pradeep, B. S. 2020. Foldscope as a Preliminary Diagnostic Tool for Field Veterinarians. Int.J.Curr.Microbiol.App.Sci. 9(09): 735-747. doi: https://doi.org/10.20546/ijcmas.2020.909.093 